Reprinted from

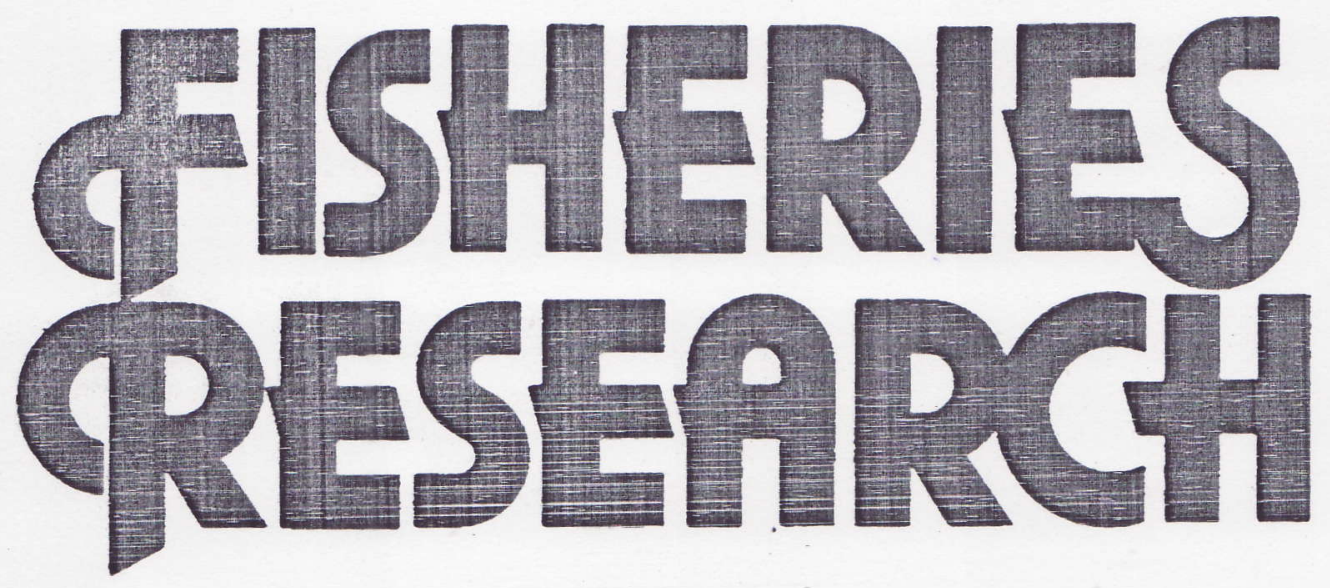

Fisheries Research 29 (1997) 33-37

The differential effects of changing management regimes on yields from two fisheries exploiting the same resources

Theodore Djama ${ }^{\text {a., }}$, T.J. Pitcher ${ }^{b}$

a Fisheries and Oceanographic Research Station, BP 343, Kribi, Cameroon

${ }^{b}$ UBC Fisheries Centre, 2204 Main Mall, Vancouver, B.C., Canada

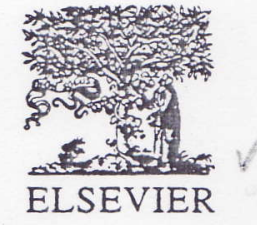

N.4.5. $9^{8}$ 


\section{THSHERIES
RESERRCH}

An international journal on fisheries science, fishing technology and fisheries management

Aims and scope. This journal provides an international forum for the publication of papers in the areas of fisheries science, fishing technology, and fisheries management. As these areas inevitably impinge on, and interrelate with each other, the approach of the journal is multidisciplinary. Authors are encouraged to emphasize the relevance of their own work to that of other disciplines covered by the journal. The scope covers salt, brackish and freshwater systems, and all aspects of fisheries, including economics, are relevant. Both practical and theoretical papers are eligible for publication. Review articles are also published The journal is intended for fisheries biologists, gear technologists, naval architects, fisheries economists, administrators, policymakers and legislators.

\section{EDITOR-IN-CHIEF}

A.D. McIntyre, Emeritus Professor, Fisheries and Oceanography, Zoology Department, University of Aberdeen, Aberdeen AB9 2TN, UK

\section{EDITORIAL ADVISORY BOARD}

K.R. Allen, Cronulla, N.S.W., Australia

T. Arimoto, Tokyo, Japan

J. Casey, Lowestoft, UK

R.H. Cook, Halifax, N.S., Canada

E.G. Dawe, St. John's, Nfld., Canada

R. Fonteyne, Ostende, Belgium

A. Guerra, Vigo, Spain

J.P. Hillis, Dublin, Ireland

E.D. Houde, Solomons, MD, USA

J.C. Howe, Mobile, AL, USA

G. Hubold, Hamburg, Germany
S.J. Lockwood, Conwy, UK

D.N. MacLennan, Aberdeen, UK

R.N. O'Boyle, Dartmouth, N.S., Canada

K. Patterson, Aberdeen,UK

J.B. Pearce, Woods Hole, MA, USA

I.G. Priede, Aberdeen, UK

A.D. Rijnsdorp, IJmuiden, Netherlands

F.M. Serchuk, Woods Hole, MA, USA

R. Shotten, Rome, Italy

D. Whitmarsh, Southsea, UK

Zhou Ying-qi, Shanghai, Peoples Republic of China

\section{Book Review Editor}

A.D. McIntyre, Aberdeen, UK

Publication information: Fisheries Research (ISSN 0165-7836). For 1997 volumes 29-33 are scheduled for publication. Subscription prices are available upon request from the Publisher. Subscriptions are accepted on a prepaid basis only and are entered on a calendar year basis. Issues are sent by surface mail except to the following countries where Air delivery via SAL mail is ensured: Argentina, Australia, Brazil, Canada, Hong Kong, India, Israel, Japan, Malaysia, Mexico, New Zealand, Pakistan, PR China, Singapore, South Africa, South Korea, Taiwan, Thailand, USA. For all other countries airmail rates are available upon request. Claims for missing issues should be made within six months of our publication (mailing) date. Please address all your requests regarding orders and subscription queries to: Elsevier Science B.V., Order Fulfilment Department, P.O. Box 211, 1000 AE Amsterdam, The Netherlands, tel. $(+31-20) 4853642$, fax $(+31-20) 4853598$.

US mailing info, Fisheries Research (ISSN 0165-7836) is published monthly except November by Elsevier Science B.V. (Molenwerf 1, Postbus 211, $1000 \mathrm{AE}$, Amsterdam). Annual subscription price in the USA US\$1281 (valid in North, Central and South America), including air speed delivery. Appli-cation to mail at second class postage rate is pending at Jamaica, NY 11431. USA POSTMASTER: Send address changes to, Fisheries Research Publications Expediting, Inc., 200 Meacham Avenue, Elmont, NY 11003. AIRFREIGHT AND MAILING in the USA by Publications Expediting Inc., 200 Meacham Avenue, Elmont, NY 11003

Back volumes: Please contact the Publisher. 


\title{
The differential effects of changing management regimes on yields from two fisheries exploiting the same resources
}

\author{
Theodore Djama ${ }^{a, *}$, T.J. Pitcher ${ }^{b}$ \\ a Fisheries and Oceanographic Research Station, BP 343, Kribi, Cameroon \\ ${ }^{b}$ UBC Fisheries Centre, 2204 Main Mall, Vancouver, B.C., Canada
}

Accepted 1 May 1996

\begin{abstract}
A yield per recruit model has been used to compare the effects of mesh size increment on the yields and revenues of the fisheries of Cameroon under two different cases. Case 1 assumes the commercial fishery to move from the exploitation of three age-groups to two age-groups with no interactions with the artisanal fishery, whereas Case 2 takes into account these interactions. The difference in the percentage increase of yield per recruit between case 1 and case 2 is $61 \%$ at current fishing ( $46 \%$ and $18 \%$ yield per recruit increment in cases 1 and 2 respectively). The usually accepted long-term yield per recruit increment with increase of age at first capture (with a single non-interacting fisheries) is, in this case, cancelled out. However, the revenues increase by $72 \%$ and $63 \%$ in cases 1 and 2 respectively. Therefore the economic approach, compared with purely biological analyses, is more convincing. In general, as fisheries always interact, a single-fishery management approach should not be the rule as it is at present; management strategies should consider interactions between different fisheries and be based on their economic performances and not, as said earlier, on purely biological considerations. This is because a biological approach to fisheries management will, at best, be modified by economic factors, or, at worst, be ignored totally in favour of economic policies.
\end{abstract}

Keywords: Interactions; Biological; Economic; Yield per recruit; Cameroon; Sciaenidae; Commercial fishery; Artisanal fishery; Management

\section{Introduction}

The commercial and artisanal fisheries in Cameroon both exploit the stock of croakers (Sciaenidae). While the commercial fishery catches juvenile and adult fish (age-groups 1, 2 and 3), the

\footnotetext{
Corresponding author.
}

artisanal fishery exploits only the adults (age-groups 2 and 3). Increasing the current stretched mesh size in use in the commercial fishery from $41 \mathrm{~mm}$ to 67 $\mathrm{mm}$, without taking into account any interaction with the artisanal fishery, gives rise to an increasing yield per recruit in the commercial fishery of $46 \%$ at current fishing effort level.

This study aims to re-evaluate the effects of this mesh size increase, taking into account the interactions between the two fisheries, and the economic implications of this policy. 


\section{Brief description of the fisheries}

Of the total fish production in Cameroon $80 \%$ comes from the artisanal fishery. The fishery itself is directed towards the capture of small pelagics mainly clupeids which are most important, and demersal resources especially croakers. There are two types of vessel currently in use: the wooden dugout canoe generally 4-7 $\mathrm{m}$ long, and the planked canoe 7-10 $\mathrm{m}$ in length. These vessels are driven either by paddles, sails, or by outboard motors usually of $8-15$ horse power. The numerous fishing gears in use fall into five categories: gillnets, falling nets, seine nets, traps and lines. For the capture of croakers, the fishing gear is gillnet with $5-7 \mathrm{~cm}$ stretched mesh size.

The commercial fishery is directed towards demersal species, $75 \%$ of which are croakers (Sciaenidae). The vessels are side trawlers ranging between 20 and $25 \mathrm{~m}$ in length, and 50 and 250 gross registered tonnes. The stretched mesh size net is $30-40 \mathrm{~mm}$ cod end (further details on this fishery can be found in Djama, 1988).

\section{The model}

To illustrate the effect on the yield per recruit of increment of age at first capture, a dynamic pool model seems to be appropriate. The first reason is that croakers investigated herein constitute an assemblage (Longhurst, 1965; Djama and Pitcher, 1989) and assessment using single-species models can be reasonably justified (Larkin, 1982). The second reason for the choice is that particular attention is given to the effects of altering the two parameters that can be directly controlled by man: i.e. the amount of fishing as measured by the fishing mortality $F$, and the way the fishing is distributed on different sizes of fish as measured by the age at first capture. We then assume (as usual) that the stock of croakers is in steady-state: i.e. the stock remains constant from one year to the next due to constant parameters of recruitment, growth and mortality. It is also assumed that there is a 'knife-edge' recruitment process happening within the age structure captured in the fisheries. Under these assumptions, the composition of the stock may then simply be calculated by consider- ing a cohort during its life-span (Beverton and $\mathrm{Hc}$ 1957). The number of fish at time $t$, can then expressed as:

$N_{t}=N_{t_{\mathrm{r}}} \mathrm{e}^{-(F+M)\left(t-t_{\mathrm{r}}\right)}$

where $N_{t \mathrm{r}}$ and $N_{t}$ are the number of fish at time recruitment and time $t$, respectively. $F$ and $M$ a fishing and natural mortality rates. The number fish dying of fishing $(C)$ during a short time interv $\left(t_{0}, t_{1}\right)$ is:

$C_{\left(t_{0}, t_{1}\right)}=\int_{t_{0}}^{t_{1}} F_{t} N_{t} \mathrm{~d} t$

Eq. (2), which represents catch in number, w fail to illustrate the importance of catching fish of particular age-group. To include the effect of age the catch equation, the weight of the fish is intr duced in the model, as most fish increase in weig with size. Eq. (2) then becomes:

$Y_{t_{1}}=\int_{t_{0}}^{t_{1}} F_{t} N_{t} W_{t} \mathrm{~d} t$

In order to solve Eq. (3), we considered $W_{t}$, derived from Brody's equation (Brody, 1927, 1945 $W_{t}=W_{\infty}\left(1-\mathrm{e}^{-k t}\right)$

$k$ here is not the von Bertalanffy growth coefficien Eq. (4) describes the adult phase of growth in weigh which is derived from a general S-shaped growt curve obtained from the plot of weight against ag (Brody, 1927, 1945). Replacing $N_{t}$ and $W_{t}$ by the: values (Eqs. (1) and (4) respectively), Eq. (3) be comes:

$Y_{t_{1}}=\int_{t_{0}}^{t_{1}} F_{t} N_{t_{\mathrm{r}}} W_{\infty} \mathrm{e}^{-(F+M) t}\left(1-\mathrm{e}^{-k t}\right) \mathrm{d} t$

Putting all the constants of Eq. (5) outside th integral we obtain:

$Y_{t_{1}}=F_{t} N_{t_{\mathrm{r}}} W_{\infty} \int_{t_{0}}^{t_{1}} \mathrm{e}^{-(F+M) t}\left(1-\mathrm{e}^{-k t}\right) \mathrm{d} t$

It is important at this point to recall that the commercial fishery catches age-groups 1,2 and: (relative years), and the artisanal fishery only age groups 2 and 3. The solution to Eq. (6) for age-groul 1 , in the commercial fishery will then be:

$$
\begin{aligned}
Y_{t_{\mathrm{lc}}}= & F_{\mathrm{c}} N_{t_{\mathrm{r}}} W_{\infty}\left(\frac{\mathrm{e}^{-\left(F_{\mathrm{c}}+M\right) t_{0}}-\mathrm{e}^{-\left(F_{\mathrm{c}}+M\right) t_{\mathrm{t}}}}{F_{\mathrm{c}}+M}\right. \\
& \left.+\frac{\mathrm{e}^{-\left(F_{\mathrm{c}}+M+K\right) t_{1}}-\mathrm{e}^{-\left(F_{\mathrm{c}}+M+k\right) t_{0}}}{F_{\mathrm{c}}+M+k}\right)
\end{aligned}
$$


$F_{\text {c }}$ represents fishing mortality from the commercial fishery alone. The yield per recruit equation for age-group 2 from the commercial fishery will be:

$$
\begin{aligned}
Y_{t_{2} \mathrm{C}}= & F_{2} N_{1} W_{\infty}\left(\frac{\mathrm{e}^{-\left(F^{\prime}+M\right) t_{1}}-\mathrm{e}^{-\left(F^{\prime}+M\right) t_{2}}}{F^{\prime}+M}\right. \\
& \left.+\frac{\mathrm{e}^{-\left(F^{\prime}+M+K\right) t_{2}}-\mathrm{e}^{-\left(F^{\prime}+M+k\right) t_{1}}}{F^{\prime}+M+k}\right)
\end{aligned}
$$

where, $F^{\prime}=F_{\mathrm{c}}+F_{\mathrm{a}}, F_{\mathrm{a}}$ being the artisanal fishing mortality. We are also recalling that $N_{1}=$ $N_{t_{\mathrm{r}}} \mathrm{e}^{-\left(F_{\mathrm{c}}+M\right)\left(t_{1}-t_{\mathrm{r}}\right)}$.

Following the reasoning above, the yield per recruit equation for age-group 3 from the commercial fishery will be:

$$
\begin{aligned}
Y_{t_{3} \mathrm{c}}= & F_{3} N_{2} W_{\infty}\left(\frac{\mathrm{e}^{-\left(F^{\prime}+M\right) t_{2}}-\mathrm{e}^{-\left(F^{\prime}+M\right) t_{3}}}{F^{\prime}+M}\right. \\
& \left.+\frac{\mathrm{e}^{-\left(F^{\prime}+M+K\right) t_{3}}-\mathrm{e}^{-\left(F^{\prime}+M+k\right) t_{2}}}{F^{\prime}+M+k}\right)
\end{aligned}
$$

The total yield per recruit from the exploitation of three age-groups in the commercial fishery will then be:

$$
\begin{aligned}
Y_{\mathrm{c}}= & \sum_{t=1}^{t=3} F_{\mathrm{c}} N_{t-1} W_{\infty} \frac{\mathrm{e}^{-\left(F^{\prime}+M\right)(t-1)}-\mathrm{e}^{-\left(F^{\prime}+M\right) t}}{F^{\prime}+M} \\
& +\frac{\mathrm{e}^{-\left(F^{\prime}+M+k\right) t}-\mathrm{e}^{-\left(F^{\prime}+M+k\right)(t-1)}}{F^{\prime}+M+k}
\end{aligned}
$$

This equation has been used to compute the various yield per recruit from the commercial fishery.

\section{Economic model}

It should be noted that fish are mostly sold in the artisanal fishery on an individual basis and not by weight. In that case, implications of the change in the management regime would be very different from those considering only catch by weight. In order to assess the economic effect of exploiting a specific age-group, we then convert the weight $W_{x}$ to price $P_{r x}$, and Eq. (10) becomes:

$$
\begin{aligned}
\mathrm{PV}_{\mathrm{c}}= & \sum_{t=1}^{t=3} F_{\mathrm{c}} N_{t-1} P_{r \infty} \frac{\mathrm{e}^{-\left(F^{\prime}+M\right)(t-1)}-\mathrm{e}^{-\left(F^{\prime}+M\right) t}}{F^{\prime}+M} \\
& +\frac{\mathrm{e}^{-\left(F^{\prime}+M+k\right) t}-\mathrm{e}^{-\left(F^{\prime}+M+k\right)(t-1)}}{F^{\prime}+M+k}
\end{aligned}
$$

Table 1

Parameters values used in the computation of various yields from the artisanal and commercial fisheries (data from Djama, 1992)

\begin{tabular}{lll}
\hline Parameter & Value & Definition \\
\hline$F_{\mathrm{c}}$ & 1.08 & Commercial fishing mortality \\
$F_{\mathrm{a}}$ & 0.42 & Artisanal fishing mortality \\
$M$ & 0.50 & Natural mortality rate \\
$k$ & 0.20 & Brody's growth coefficient \\
$W_{\infty}$ & 3260 & Average infinite weight \\
$P_{r \infty}$ & US $\$ 0.7,1.6,2$ & Prices of age-groups 1,2 and 3 \\
$N_{t r}$ & 1000 & Initial number of recruits \\
\hline
\end{tabular}

$P_{\infty}$ is proportional to the age-group and was taken as $0.7,1.6$ and 2 US\$ for age-groups 1,2 and 3 respectively. $N_{t r}{ }^{*}$ : the initial number of recruits is unrealistic, but, if changed, does not affect the results.

where $\mathrm{PV}_{\mathrm{c}}$ is the revenue (or present value) accrued in exploiting three age-groups (1,2 and 3$)$ in the commercial fishery. It will be necessary to assume for simplicity that fish price is proportional to size, remains constant, and that the discount rate is zero. To that end, fish prices of age-groups 1, 2 and 3 were assumed to be US\$ $0.7,1.6$ and 2 respectively.

In the following, two cases are considered. Case 1 , assumes the industrial fishery to move from the exploitation of age-groups 1,2 and 3, to only agegroups 2 and 3 , without taking into account the fishing mortality of the artisanal fishery. In other words, case 1 illustrates a situation whereby fisheries are studied or managed in isolation.

Case 2 is the repetition of case 1 , with the fishing mortality of the artisanal fishery taken into account. This case illustrates the ideal situation whereby interactions between various fisheries are taken into account in studies and/or management of fisheries.

Table 2

Exploitation scenario of case 1, which moves from exploitation of three age-groups to only two age-groups without considering the effects of the artisanal fishery

\begin{tabular}{llc}
\hline & \multicolumn{2}{l}{$\%$ increase } \\
\cline { 2 - 3 } & Commercial & Artisanal \\
\hline Case 1 & 84 & 10 \\
Case 2 & 26 & 398 \\
\hline
\end{tabular}




\section{Results and discussion}

Table 1 shows the parameters (taken from Djama, 1992) used in the computation of yield per recruit curves. The increase of yield per recruit in case 1 is $46 \%$ at current fishing level in the commercial fishery (Table 2), whereas the revenue increases by
$72 \%$. Case 2, which includes the fishing mortality of the artisanal fishery, indicates an increase in yield per recruit of $18 \%$ at current fishing levels and of revenue by $63 \%$ (Table 3 ).

Basically, these results are not surprising, as from the model itself one could expect a relative reduction of the yield per recruit in the commercial fishery

Table 3

Exploitation scenario of case 2, which moves from exploitation of three age-groups to only two age-groups, this time taking into account the fishing mortality of the artisanal fishery

\begin{tabular}{|c|c|c|c|c|c|c|c|c|c|}
\hline \multicolumn{5}{|c|}{ Exploitation of three age-groups } & \multicolumn{3}{|c|}{ Exploitation of two age-groups } & \multicolumn{2}{|c|}{ Percentage increase } \\
\hline Effort & Age 1 & Age 2 & Age 3 & Total & Age 2 & Age 3 & Total & Yield & Revenue \\
\hline 0.1 & 20749 & 2539 & 259 & 23546 & 33143 & 1425 & 34568 & 32 & 66 \\
\hline 0.2 & 38990 & 4066 & 406 & 43462 & 60028 & 2518 & 62546 & 31 & 66 \\
\hline 0.3 & 54985 & 4885 & 478 & 60348 & 81749 & 3354 & 85103 & 29 & 66 \\
\hline 0.4 & 68968 & 5211 & 501 & 74681 & 99209 & 3992 & 103200 & 28 & 65 \\
\hline 0.5 & 81151 & 5201 & 493 & 86845 & 113154 & 4474 & 117627 & 26 & 65 \\
\hline 0.6 & 91723 & 4968 & 466 & 97156 & 124200 & 4835 & 129035 & 25 & 65 \\
\hline 0.7 & 100855 & 4593 & 428 & 105877 & 132857 & 5102 & 137959 & 23 & 65 \\
\hline 0.8 & 108702 & 4136 & 386 & 113225 & 139546 & 5295 & 144841 & 22 & 64 \\
\hline 0.9 & 115403 & 3640 & 343 & 119385 & 144615 & 5430 & 150045 & 20 & 64 \\
\hline 1 & 121080 & 3133 & 301 & 124514 & 148351 & 5520 & 153871 & 19 & 64 \\
\hline $1.1^{* * *}$ & 125847 & 2637 & 261 & 128746 & 150993 & 5573 & 156566 & $18^{* * *}$ & $63^{* * *}$ \\
\hline 1.2 & 129804 & 2164 & 226 & 132194 & 152738 & 5599 & 158337 & 17 & 63 \\
\hline 1.3 & 133041 & 1725 & 193 & 134959 & 153748 & 5602 & 159351 & 15 & 63 \\
\hline 1.4 & 135640 & 1322 & 165 & 137127 & 154160 & 5588 & 159748 & 14 & 62 \\
\hline 1.5 & 137672 & 960 & 140 & 138772 & 154083 & 5561 & 159644 & 13 & 62 \\
\hline 1.6 & 139204 & 639 & 118 & 139961 & 153611 & 5522 & 159133 & 12 & 62 \\
\hline 1.7 & 140293 & 356 & 100 & 140749 & 152820 & 5476 & 158296 & 11 & 61 \\
\hline 1.8 & 140992 & 111 & 84 & 141188 & 151773 & 5423 & 157196 & 10 & 61 \\
\hline 1.9 & 141349 & -98 & 70 & 141321 & 150523 & 5366 & 155888 & 9 & 61 \\
\hline 2 & 141405 & -275 & 59 & 141189 & 149112 & 5305 & 154416 & 9 & 60 \\
\hline 2.1 & 141199 & -423 & 49 & 140825 & 147576 & 5241 & 152817 & 8 & 60 \\
\hline 2.2 & 140762 & -544 & 41 & 140260 & 145946 & 5175 & 151121 & 7 & 60 \\
\hline 2.3 & 140127 & -641 & 34 & 139520 & 144244 & 5109 & 149353 & 7 & 60 \\
\hline 2.4 & 139319 & -717 & 28 & 138630 & 142492 & 5041 & 147533 & 6 & 59 \\
\hline 2.5 & 138362 & -774 & 24 & 137611 & 140705 & 4974 & 145679 & 6 & 59 \\
\hline 2.6 & 137278 & -815 & 20 & 136482 & 138898 & 4906 & 143804 & 5 & 59 \\
\hline 2.7 & 136086 & -843 & 16 & 135260 & 137080 & 4839 & 141919 & 5 & 59 \\
\hline 2.8 & 134803 & -858 & 13 & 133958 & 135261 & 4772 & 140033 & 4 & 59 \\
\hline 2.9 & 133444 & -863 & 11 & 132591 & 133449 & 4706 & 138155 & 4 & 59 \\
\hline 3 & 132021 & -860 & 9 & 131170 & 131649 & 4641 & 136290 & 4 & 59 \\
\hline 3.1 & 130548 & -850 & 8 & 129705 & 129867 & 4576 & 134443 & 4 & 58 \\
\hline 3.2 & 129033 & -834 & 6 & 128206 & 128105 & 4513 & 132617 & 3 & 58 \\
\hline 3.3 & 127488 & -813 & 5 & 126680 & 126366 & 4451 & 130817 & 3 & 58 \\
\hline 3.5 & 124334 & -762 & 4 & 123576 & 122969 & 4330 & 127299 & 3 & 58 \\
\hline 3.6 & 122739 & -733 & 3 & 122009 & 121314 & 4271 & 125585 & 3 & 58 \\
\hline 3.7 & 121140 & -702 & 2 & 120440 & 119688 & 4213 & 123901 & 3 & 58 \\
\hline 3.8 & 119541 & -670 & 2 & 118872 & 118094 & 4156 & 122250 & 3 & 58 \\
\hline 3.9 & 117946 & -638 & 2 & 117310 & 116530 & 4101 & 120631 & 3 & 58 \\
\hline 4 & 116360 & -606 & 1 & 115756 & 114997 & 4047 & 119044 & 3 & 58 \\
\hline
\end{tabular}

*** Values representing either the actual fishing mortality or the related percentage increase of yield and revenue. 
with the inclusion of the fisting mortality from the artisanal fishery. However, the difference in the percentage increase of the yield per recruit $(61 \%)$ between cases 1 and 2 is so high that it cancels out the policy of long-tern yield per recruit increment with increase of age at first capture. As can be seen, and particularly where yield per recruit is concerned, cases 1 and 2 lead to two conflicting arguments, the first for and the second against the increase of age at first capture in the fisheries ( $46 \%$ increment in case 1 and only $18 \%$ in case 2 ).

Adopting the economic performance as a management strategy of the fishery, things appear more clear. In fact, the revenues of the commercial fishery increase by $72 \%$ and $63 \%$ in Cases 1 and 2 respectively. This proves that, the fishery is economically healthy in both cases. Therefore, when fisheries are interacting, mesh size increment policy, with a view of economic performance of the sector, is more appropriate than the classic yield per recruit increment strategy. To that end, better management of either the commercial or the artisanal fisheries of Cameronn should include interactions between these.

These results once more confirm the fact that advice based on economic factors are better tools in fisheries management than those based purely on biological analyses. The foregoing has also demonstrated the extent to which one can be biased in studying fisheries in isolation, without taking into account their interactions. This suggests that the single-fishery management approach ought to cease being the rule as it is at present; management strategies should consider interactions between different fisheries, and be based on their economic performance and not on purely biological analyses, because the biological approach to fisheries management will, at best, be modified by economic factors or, at worst, be ignored totally in favour of economic policies.

This example is not a panacea or unique in its kind, but shows, among other possible examples, how one can reach a better understanding of a particular fishery.

\section{Acknowledgements}

We are indebted to the Renewable Resources Assessment Group (Imperial College, London) for their assistance during the course of this work, and especially in the setting up of the model.

\section{References}

Beverton, R.J.H. and S.J. Holt, 1957. On the dynamics of exploited fish populations. Fish. Invest. Minist. Agric. Fish Food G.B. Ser. II Sea Fish, 19: 1-533.

Brody, S., 1927. Growth rates. Mo. Agric. Exp. Stn. Bull. 97.

Brody, S., 1945. Bioenergetics and Growth. Reinhold, New York.

Djama, T., 1988. Estimation of growth parameters and mortality of longneck croaker Pseudotolithus typus in Cameroon. Contribution to tropical fisheries biology. FAO Fish. Rep., 389: $153-170$.

Djama, T., 1992. Interactions between the artisanal and the industrial fisheries of Cameroon. Ph.D. Thesis, University of Wales, $210 \mathrm{pp}$

Djama, T. and Pitcher, T.J., 1989. Comparative stock assessment of two sciaenid species, Pseudotolithus typus (Bleeker, 1863) and Pseudotolithus senegalensis (Valencienne, 1833) off Cameroon. Fish. Res., 7: 111-125.

Larkin, P.A., 1982. Directions for future research in tropical multi-species fisheries. In: D. Pauly and G.I. Murphy (Editors), Theory and Management of Tropical Fisheries. ICLARM Conference Proceedings 9, pp. 309-328.

Longhurst, A.R., 1965. A survey of the fish resources of the Eastern Gulf of Guinea. J. Conserv. CIEM, 29(3): 302-334. 